\title{
BMJ Open Costs of hospital trauma team simulation training: a prospective cohort study
}

\author{
Eerika Rosqvist (10 , ${ }^{1}$ Marika Ylönen, ${ }^{2}$ Paulus Torkki, ${ }^{3}$ Jussi P Repo,,${ }^{4,5}$ \\ Juha Paloneva ${ }^{6,7}$
}

To cite: Rosqvist $E$, Ylönen $M$, Torkki P, et al. Costs of hospital trauma team simulation training: a prospective cohort study. BMJ Open 2021;11:e046845. doi:10.1136/ bmjopen-2020-046845

- Prepublication history and supplemental material for this paper is available online. To view these files, please visit the journal online (http://dx.doi. org/10.1136/bmjopen-2020046845).

Received 20 November 2020 Accepted 14 May 2021

Check for updates

(c) Author(s) (or their employer(s)) 2021. Re-use permitted under CC BY-NC. No commercial re-use. See rights and permissions. Published by BMJ.

For numbered affiliations see end of article.

Correspondence to Dr Eerika Rosqvist; eerika.rosqvist@ksshp.fi

\section{ABSTRACT}

Objectives This study investigated the costs of 2-hour multiprofessional in situ hospital trauma team simulation training and its effects on teams' non-technical skills using the T-NOTECHS instrument.

Background Simulation is a feasible and effective teaching and learning method. Calculating the costs of simulated trauma team training in medical emergency situations can yield valuable information for improving its overall cost-effectiveness.

Design A prospective cohort study.

Setting Trauma resuscitation room in Central Finland Hospital, Finland.

Participants 475 medical professionals in 81

consecutive, simulated trauma teams.

Primary and secondary outcome measures Team simulation training costs in 2017 and 2018 were analysed in the following two phases: (1) start-up costs and (2) costs of education. Primary outcome measures were training costs per participant and training costs per team. Secondary outcome measures were non-technical skills, which were measured on a 5-25-point scale using the T-NOTECHS instrument.

Results The annual mean total costs of trauma team simulation training were $€ 58000$ for 40 training sessions and 238 professionals. Mean cost per participant was $€ 203$. Mean cost per team was $€ 1220$. The annual costs of simulation training markedly decreased when at least 70-80 teams participated in the training. Mean change in T-NOTECHS score after simulation training was +2.86 points $(95 \% \mathrm{Cl} 1.97$ to $3.75 ;+14.5 \%)$.

Conclusions The greater the number of teams trained per year, the lower the costs per trauma team. In this study, we developed an activity-based costing method to calculate the costs of trauma team simulation training to help stakeholders make decisions about whether to initiate or increase existing trauma team simulation training or to obtain these services elsewhere.

\section{INTRODUCTION}

Simulation training is effective in educating healthcare professionals. ${ }^{12}$ It is time-efficient, shortens the learning curve and leads to fewer treatment errors, all of which reduce longterm healthcare costs. ${ }^{3}$ Simulation is feasible and effective in specialised acute settings, such as emergency departments. ${ }^{4}$

\section{Strengths and limitations of this study}

- All the cost-related data were obtained from reliable sources, yielding reliable estimates of real-world costs.

- The cost components of the trauma team simulation training course were calculated in detail and thoroughly analysed in the following two phases: startup costs and costs of education.

- These cost analyses cannot be readily generalised to other countries or simulation environments, as other countries and centres are likely to have different cost structures and price levels.

- The T-NOTECHS scale has demonstrated strong structural validity and acceptable reliability for assessing performance in simulation-based multiprofessional trauma team resuscitations.

- Adhering to rigorous translation and cross-cultural adaptation guidelines for instruments rating nontechnical skills, a Finnish version of the T-NOTECHS scale has been developed.

Reports on the costs of simulation-based medical education research are few. ${ }^{5}{ }^{6}$ In their review, Zendejas et a $\breve{l}$ found that costs were mentioned in only 59/967 studies on simulation-based medical education. Thus, the literature fails to provide consistent and interpretable information on the relative costs of simulation-based education. ${ }^{6}$ The resources required to implement simulationbased education have led some stakeholders to question its overall value. ${ }^{2}$

The primary aims of a trauma team are to rapidly resuscitate and stabilise a potentially critically injured patient, prioritise and determine the nature and extent of the injuries, and, according to the predetermined protocol, prepare the patient for transport to the site of definitive care. ${ }^{78}$ In this study, the educational goals of the trauma team simulation course focused on improving team members' non-technical skills. ${ }^{9}$

Computerised patient simulator-based multiprofessional trauma team training 
started in 2009 in the Central Finland Central Hospital $(\mathrm{CFCH})$ hospital and has since been used as a regular teaching and learning method to improve and maintain teams' performance. The positive effects of this short-structured 2-hour in situ trauma team simulation training course in improving the non-technical skills of hospital trauma teams has been confirmed. ${ }^{9}$ However, the real costs of the course have not previously been calculated. Moreover, to the best of the authors' knowledge, no previous studies have been published on the costs of hospital trauma team simulation training courses or programmes. Calculating the real costs can yield valuable information for improving overall cost-effectiveness, for example, the number of teams trained per year required to reduce the costs of these courses.

This study, implemented in the Central Finland Hospital (CFH), investigated the costs of a 2-hour multiprofessional in situ hospital trauma team simulation training course and its effects on teams' non-technical skills using the T-NOTECHS instrument.

\section{MATERIALS AND METHODS}

The CFH, Jyväskylä, Finland, is the only hospital with an around-the-clock emergency department and the only provider of public secondary care in its catchment area, which has a population of 275000 . As defined by the American Trauma Society, CFH is a level II/III trauma centre with 24-hour coverage by emergency medicine physicians, residents mastering the field of general surgery, orthopaedic surgery, gastrointestinal surgery, anaesthesiology, radiology and critical care.

CFH's Center of Medical Expertise is one of the Network of Accredited Skills Centres in Europe. In CFH, trauma team simulation training is being developed for specialists and residents as well as for trauma and other nurses working in the emergency department, intensive care unit (ICU) and postanaesthesia care unit. Minimally, the trauma team includes a surgeon, an anaesthesiologist, a radiologist, a trauma nurse and another nurse paired with the anesthesiologist. Surgeons, anaesthesiologists and nurses participate in simulation training once or twice per year.

The structured 2-hour trauma team simulation courses reported on in this study were conducted in a real hospital environment ('in situ') in CFH's emergency department and ICU. All the simulations performed in 2017 and 2018 were included. Participants included surgeons, anaesthesiologists, radiologists and nurses, and they acted in their real-life professional roles. The 2-hour course comprised either one simulation per course (pregnant patient scenario in spring 2017 and emergency laparotomy scenario in spring 2018) or two simulations per course (thoracic injury scenarios in autumn 2017 and car crash scenarios in autumn 2018). The course included either (1) clarifying the method, (2) an introductory lecture, (3) assuming roles, (4) first simulation and debriefing and (5) second simulation and debriefing or (1) clarifying the method, (2) an introductory lecture, (3) assuming roles and (4) simulation and debriefing. The following three different computer-based adult patient simulators were used: the HAL S3201 (Gaumard, Nordic Simulators Oy), SimMom (Laerdal) and Ambu Man (Ambu).

The main simulation training instructor was a senior anaesthesiologist and intensivist who had participated in the European Trauma Course, the Finnish simulation instructor basic course and Generic Instructor Course. He was paired (one at a time) with three nurse teachers (specialised in anaesthesia, ICU and ER, respectively), who acted as simulator pilots. Nurse teachers have also participated in the Finnish basic simulation instructor

Table 1 Examples of simulation scenario descriptions

\begin{tabular}{|c|c|}
\hline Simulation description & Examples of trauma care procedures \\
\hline $\begin{array}{l}\text { Simulation IA: A } 21 \text {-year-old woman who had been stabbed multiple times: several } \\
\text { stab wounds to upper body and head (slight bleeding), limbs (barely bleeding) and } \\
\text { neck (profuse bleeding). } \\
\text { On arrival at ER, patient conscious and confused, GCS } 13 \text {. Airway open, decreased } \\
\text { BS on left side, RF } 35, \mathrm{SpO}_{2} 90 \%, \mathrm{BP} 98 / 62, \mathrm{HR} 118 \text {. Thoracic crackles on left side. }\end{array}$ & $\begin{array}{l}\text { Intubation } \\
\text { Tension pneumothorax relief using thoracocentesis } \\
\text { or a pleural drain } \\
\text { Bleeding control }\end{array}$ \\
\hline $\begin{array}{l}\text { Simulation IB: A 44-year-old woman who had been stabbed multiple times: several } \\
\text { stab wounds to body. Escaped perpetrator, fell and hit her head. } \\
\text { On arrival at ER, patient unconscious, GCS } 8 \text {. Airway open, decreased BS on left side, } \\
\mathrm{RF} 34, \mathrm{SpO}_{2} 87 \% \text {, BP } 72 / 54, \mathrm{HR} 116 \text {. }\end{array}$ & $\begin{array}{l}\text { Same as simulation IA } \\
\text { Decision-making }\end{array}$ \\
\hline $\begin{array}{l}\text { Simulation IIA: A } 45-\text { year-old man who had been in a two-car collision. Local } \\
\text { speed limit } 80 \mathrm{~km} / \text { hours. Patient had been trapped in his car. Complained of pain } \\
\text { in thorax and pelvis. Patient conscious and confused, GCS } 14-15 \text {. Airway open, no } \\
\text { BS on left side, RF elevated, } \mathrm{SpO}_{2} 92 \%-93 \% \text {, BP } 150 / 90, \mathrm{HR} 100 \text {. Pelvis stable, } \\
\text { hemopneumothorax and three costa fractures on left side. }\end{array}$ & $\begin{array}{l}\text { FAST } \\
\text { Tension pneumothorax relief using a pleural drain }\end{array}$ \\
\hline $\begin{array}{l}\text { Simulation IIB: Same patient as IIA. Airway open, no BS on left side, RF }>20 \text {, } \\
\text { shortness of breath, } \mathrm{SpO}_{2} 89 \%-90 \% \text { with oxygen, BP } 110 / 60 \text {, HR } 110 \text {. GCS shows } \\
\text { fall from } 11 \text { to } 7 \text {. Pelvis unstable, hemopneumothorax and five costa fractures on left } \\
\text { side, open book pelvis fracture, small subdural hematoma on right side. }\end{array}$ & $\begin{array}{l}\text { Same as simulation IIA } \\
\text { Intubation } \\
\text { Pelvic stabilisation using a pelvic binder (T-POD) }\end{array}$ \\
\hline
\end{tabular}

BP, blood pressure; BS, breathing sounds; ER, emergency room; FAST, Focused Assessment with Sonography for Trauma; GCS, Glasgow Coma Scale; HR, heart rate; RF, respiratory frequency; $\mathrm{SpO}_{2}$, blood oxygen saturation level. 
course. Each team also includes a technical assistant, who conducts the simulations.

The simulated patient scenarios were changed twice a year. The introductory lecture topics and two simulated scenarios are described in table 1 . We used the data on these two simulation scenarios (four cases in total).

After the study was approved by the Central Finland Health Care District's institutional review board, the data collection started. Data were collected prospectively and anonymously between 2017 and 2018 by expert raters (an anaesthesiologist and a nurse teacher) using the T-NOTECHS scale. ${ }^{10}$ Answering the self-assessment questionnaire was voluntary. The courses were attended by 475 participants in 81 teams. The cost-related data were collected between January and March 2019.

\section{Patient and public involvement \\ No patient involvement.}

\section{Instrument}

T-NOTECHS scale

T-NOTECHS scale was developed to assess non-technical skills in trauma team resuscitation. ${ }^{11}$ The T-NOTECHS scale comprises the following five categories of teamwork behaviours: leadership, cooperation and resource management, communication and interaction, assessment and decision-making, and situation awareness/ coping with stress. Each category is scored on a 5-point scale (range: 5-25 points). The lowest score indicates the total absence of the teamwork behaviour and the highest score flawless teamwork behaviour.

Adhering to rigorous translation and cross-cultural adaptation guidelines for non-technical skills rating instruments, a Finnish version of the T-NOTECHS scale has been developed. ${ }^{12}$ The scale has proven to have strong structural validity and acceptable reliability for assessing performance in simulation-based multiprofessional trauma team resuscitations. ${ }^{10}$ It has also been widely adopted for assessing simulation performance. $.^{911} 13-23$

\section{Cost components}

Team simulation training was analysed in two phases: (1) start-up costs and (2) costs of education. The start-up costs included the costs of equipment, the training courses attended by the training instructors, planning, and the salaries of instructors, nurse teachers, educational designers and technical specialists before education. The education costs included the salaries of the participants and instructors during the education and the costs of materials, maintenance of equipment and hiring spaces.

Data were obtained from multiple sources: the use of personnel resources was estimated by interviewing the training instructor and educational designer. Salaries (including indirect costs) and the costs of equipment, materials and hiring spaces were collected from $\mathrm{CFCH}$ databases.

The costs of personnel and spaces were analysed using simplified activity-based costing logic. The cost of each activity was calculated by multiplying its duration by its unit costs. Equipment, maintenance and material costs were extracted directly from $\mathrm{CFCH}$ databases. Depreciation over 10 years with a $3 \%$ interest rate was used for equipment. Costs of salaries and spaces were determined by the duration of the simulation. For example, if a room was reserved for 8 hours, the cost per hour was multiplied by number of hours actually used. Correspondingly, personnel costs were calculated by multiplying the duration of the simulation in hours by total salary costs per hour, including overheads.

The primary outcome measures were training costs per participant and training cost per team. Training costs were divided into two categories: participants' salaries and training costs.

\section{Statistical analysis}

The T-NOTECHS-related data were analysed with SPSS, V.25. The results were presented as frequency and percentage distributions with SD. A CI of $95 \%$ and paired-samples t-test were used as analytical methods. A p value of $<0.05$ was considered significant. Inter-rater reliability between the expert raters was calculated using intraclass correlation coefficients (ICCs). The ICC value was classified according to Cicchetti et $a l^{24}$ as poor $(<0.40)$, fair $(0.40-0.59)$, good $(0.60-0.74)$ or excellent (0.75-1.00).

\section{RESULTS \\ Costs}

In total, we analysed 81 teams, 124 simulations and 475 participants. The mean total costs of simulation training were $€ 58000$ per year (€53 000 in 2017 and $€ 63000$ in 2018; figure 1). Education costs accounted for $53 \%$ and start-up costs for $47 \%$ of total costs. In the start-up phase, equipment accounted for $85 \%$ and the instructor-training courses for $15 \%$ of costs. Personnel costs accounted for $94 \%$ of the costs in the education phase.

Mean cost per participant was $€ 203$ and mean cost per team $€ 1220$. Participant salaries formed $32 \%$ and training costs $68 \%$ of total costs. Since the initial investment costs were high, the mean cost per team was reduced by increasing the number of teams trained (figure 2).

\section{T-NOTECHS mean score}

Online supplemental files 1 and 2 demonstrate the trauma teams' non-technical skills after the first and second simulations ( $\mathrm{N}=41$ teams, 225 participants). Tables 2 and 3 show the improvement in the T-NOTECHS mean scores after the first and the second simulations.

According to the evaluation of the four raters, the mean change in the T-NOTECHS score was +2.86 points ( $95 \%$ CI 1.97 to $3.75 ;+14.5 \%)$. The cost per one-point increase in teamwork performance (T-NOTECHS score) was $€ 427$.

\section{Inter-rater reliability for T-NOTECHS}

The inter-rater agreement between two raters for T-NOTECHS after the one-simulation $(\mathrm{n}=76)$ and 
70000
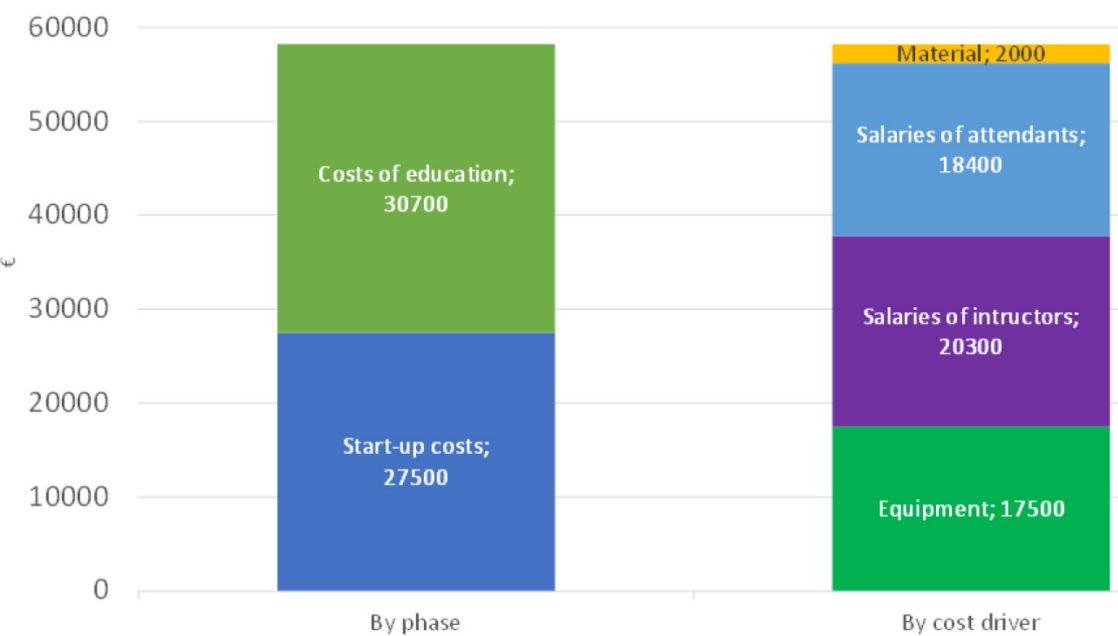

By cost driver

Figure 1 Total costs of simulation training per year in 2017-2018 (40 teams and 238 participants per year).

two-simulation $(\mathrm{n}=55)$ courses was good and fair (ICC $=0.67,95 \%$ CI 0.48 to 0.79 and ICC $=0.53,95 \% \mathrm{CI}$ 0.20 to 0.72 , respectively). The inter-rater agreement between two raters for T-NOTECHS after all the simulations $(\mathrm{N}=131)$ was good (ICC=0.69, $95 \%$ CI 0.56 to 0.78$)$.

\section{DISCUSSION}

This study analysed the costs trauma team simulation training and its effects on non-technical skills as evaluated with the T-NOTECHS instrument. Mean cost per participant was $€ 203$ and the mean cost of the whole team simulation was $€ 1220$. The simulation training costs markedly decreased when at least 70-80 teams participated annually in the training. The mean change in the T-NOTECHS score after the simulation training was +2.86 points. The cost per one-point increase in teamwork performance (T-NOTECHS score) was $€ 427$. These results can be used as a benchmark for further studies.

Personnel salaries per year amounted to $€ 20300$. The one-simulation case in spring 2018 (emergency laparotomy) increased salary costs, as the simulation ended in the ICU and almost all the teams had three instructors (90 hours of specialists teaching in spring 2018 compared with 34 hours in spring 2017). This indicates that the more complex the patient case, the greater the number of specialists needed to teach multiprofessional teams.

The results show that the present training volume $(81$ simulations) in the CFH was not optimal with regard to

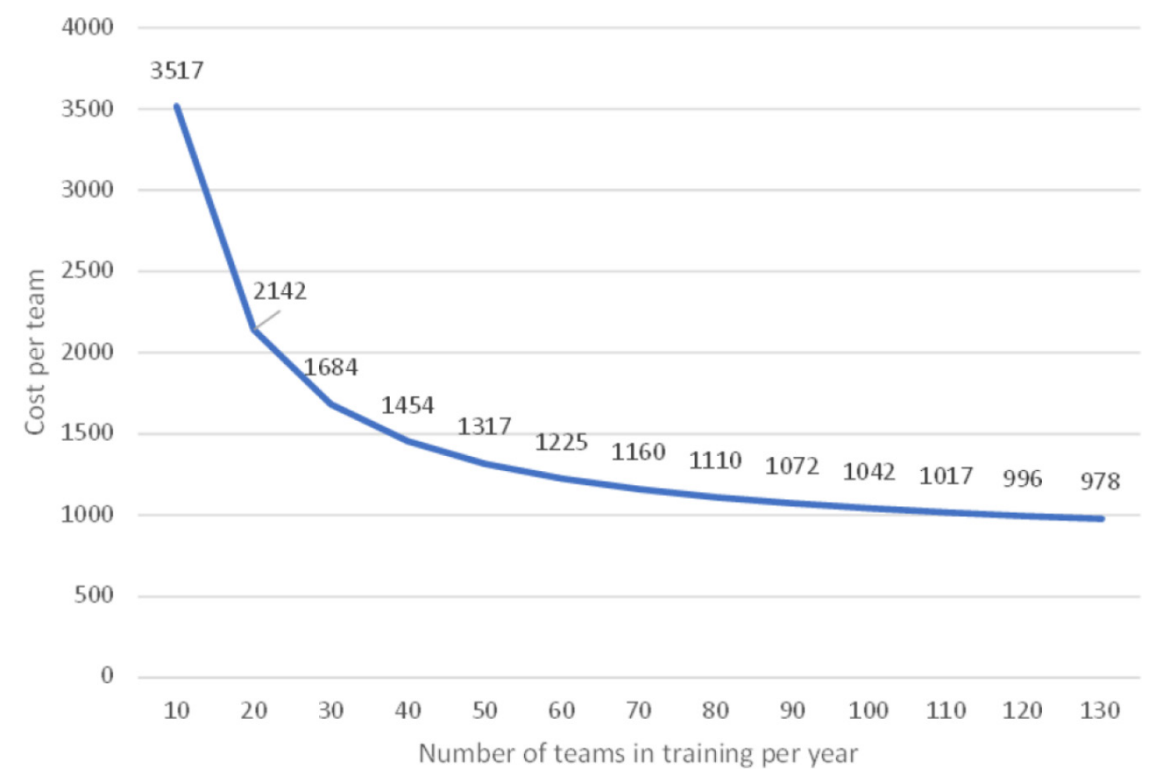

Figure 2 Cost per team as a function of the number of teams in training per year (the results are computational from team number 82 onwards). 

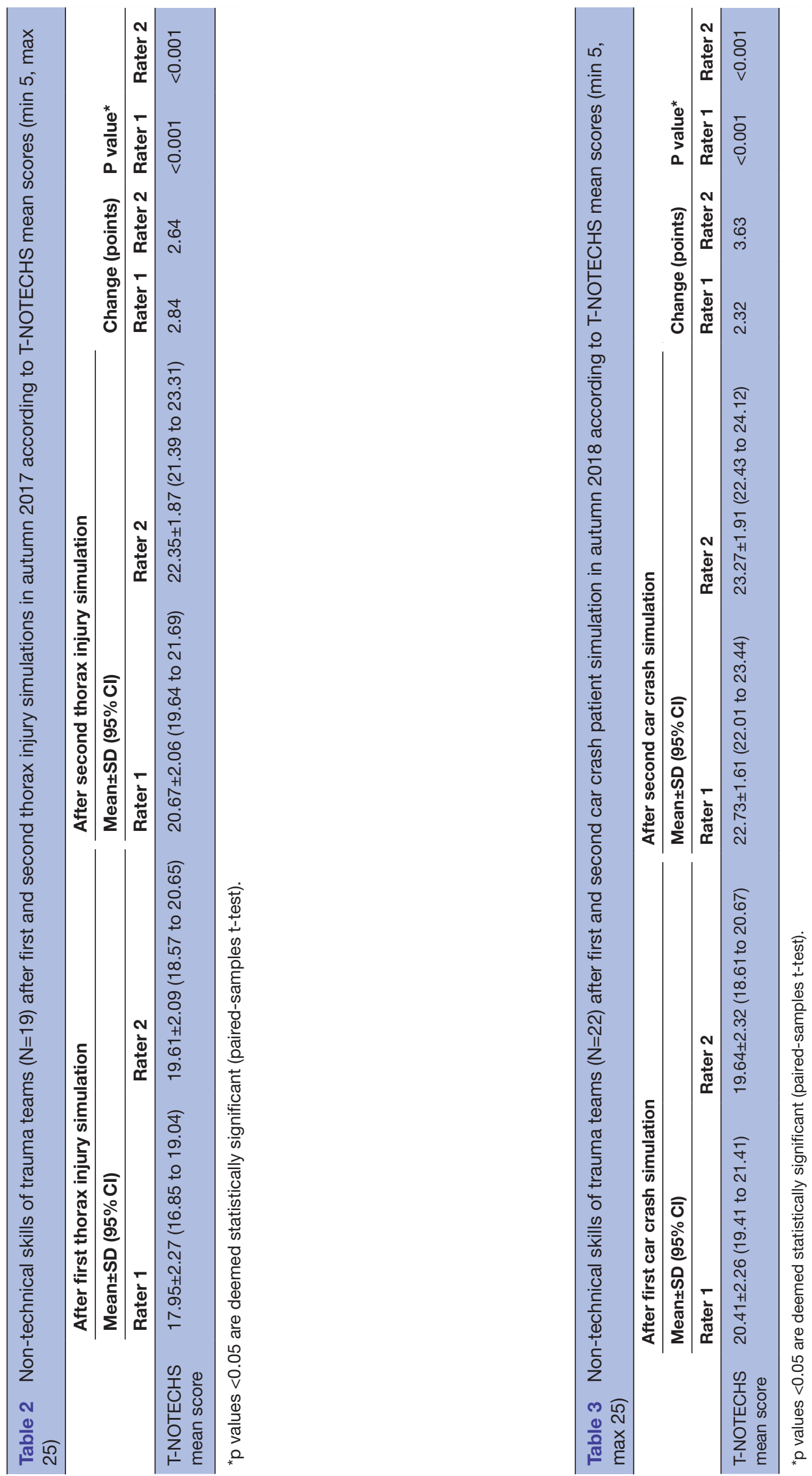

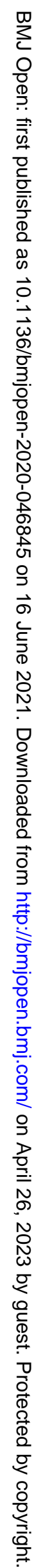


costs, as the costs per team fell, the greater the number of trauma teams trained per year. Thus, it might lower costs to increase the number of trauma teams receiving simulation training or to sell the simulation concept, teachers, and equipment to other hospitals. This accords with the finding of Jensen $e t a l,{ }^{25}$ who studied the implementation barriers related to simulation-based training for trauma resuscitation in centres using and not using simulationbased training. They found that funding faculty or staff time to participate in the session and funding to run the sessions were commonly rated barriers in both groups. Funding to purchase simulators was ranked as the greatest barrier in centres not using simulation-based training. These funding barriers were negatively associated with number of annual simulation-based training sessions. They concluded that strategies to share resources, thereby decreasing costs, may improve the usage of simulationbased training.

In this study, the non-technical skills of the participating trauma teams improved statistically significantly after the simulation training course when evaluated using the T-NOTECHS instrument. Non-technical skills training has been identified as an important contributor to improved patient safety. ${ }^{26}$ Good non-technical skills allow healthcare providers to concentrate more on the technical side of the task. For example, delegating subtasks to team members reduces one's own workload and introduces an additional safety layer in technical performance. ${ }^{26}$ Good non-technical performance is also associated with a significant decrease in disposition time. ${ }^{16}$ However, certain combinations of non-technical skills are more effective than others in different contexts. ${ }^{26}$ To avoid these possible confounding effects, we used T-NOTECHS, an instrument specifically developed for evaluating trauma team resuscitations.

Trauma team simulation training per se, has many positive influences on patient-related outcomes. Trauma teams have been shown to reduce time to CT scan and secondary survey of the patient; in other words, assessment time has been reduced. ${ }^{27}$ Knobel $e t a t^{8}$ found a significant decrease in time spent on real trauma resuscitation from patient arrival at the emergency department to CT scan after simulation training. As emergency department length of stay is an independent predictor of hospital mortality following trauma activation, teambased simulation training has the potential to improve patient outcomes. ${ }^{27}$

In sum, the economic evaluation of simulation-based training programmes or curricula is required to determine whether the improvement effected in trainee performance (knowledge, skills and attitudes) and health outcomes justifies the investment cost. ${ }^{6}$ When deciding whether to purchase potentially expensive simulation training programmes, it is important that administrators are well informed about their clinical and economic effects. ${ }^{29}$ Future work should focus on both costs and outcomes, with robust measures of resource investments, provider performance, patient outcomes and impact on the healthcare organisation. ${ }^{2}$ It must, however, be conceded that measuring real-life patient outcomes is challenged by many confounding factors.

\section{Limitations and strengths of the study}

A strength of this study is that all the cost-related data were obtained from reliable sources, yielding reliable estimates of real-world costs. Another strength is that the cost components of the trauma team simulation training programme were calculated in detail and thoroughly analysed in two phases: start-up costs and education costs. A properly conducted economic evaluation can help stakeholders to determine the optimal use of resources when selecting, for example, the simulation modality or method of assessment. ${ }^{6}$

A limitation of this study is that these cost analyses cannot be readily generalised to other countries or simulation environments. The obvious reason for this is that other countries and centres are likely to have different cost structures and price levels. Nevertheless, the information yielded by this study may be of value in designing trauma team simulations and estimating their costs. This in turn may help to provide estimations of the true costs of simulation training for policymakers and stakeholders.

\section{CONCLUSION}

The results showed that the greater the number of teams trained per year, the lower the costs per structured 2-hour session of in situ hospital trauma team simulation training. This study developed an activity-based costing method to calculate the costs of trauma team simulation training, helping stakeholders to make decisions about whether to initiate or increase existing trauma team simulation training or to obtain these services elsewhere.

\section{Author affiliations}

${ }^{1}$ Department of Educational Services, The Center of Medical Expertise, Central Finland Central Hospital, Jyvaskyla, Finland

${ }^{2}$ Department of Anesthesiology and Intensive Care, Central Finland Central Hospital, Jyvaskyla, Finland

${ }^{3}$ Department of Public Health, Helsingin Yliopisto, Helsinki, Finland

${ }^{4}$ Department of Orthopaedics and Traumatology, Unit of Muskuloskeletal Surgery, Tampere University Hospital, Tampere, Finland

${ }^{5}$ University of Tampere, Tampere, Finland

${ }^{6}$ Department of Surgery, Central Finland Central Hospital, Jyvaskyla, Finland

${ }^{7}$ University of Eastern Finland, Kuopio, Finland

Contributors ER, MY, PT, JPR and JP: substantial contribution to the concept and design of the work; and acquisition, analysis and interpretations of data; have drafted the article and revised it critically for important intellectual content; have approved the version to be published and have participated sufficiently in the work to take public responsibility for appropriate portions of the content.

Funding The authors have not declared a specific grant for this research from any funding agency in the public, commercial or not-for-profit sectors.

Competing interests None declared.

Patient consent for publication Not required.

Ethics approval This study was approved by the Central Finland Healthcare District's institutional review board and scientific research application form was signed by Medical Director of the Central Finland Healthcare District, 2 October 2015. There is no number/ID in approved application form. 
Provenance and peer review Not commissioned; externally peer reviewed.

Data availability statement Data are available upon reasonable request. Technical appendix and statistical code and data set available from the corresponding author at eerika.rosqvist@ksshp.fi.

Supplemental material This content has been supplied by the author(s). It has not been vetted by BMJ Publishing Group Limited (BMJ) and may not have been peer-reviewed. Any opinions or recommendations discussed are solely those of the author(s) and are not endorsed by BMJ. BMJ disclaims all liability and responsibility arising from any reliance placed on the content. Where the content includes any translated material, BMJ does not warrant the accuracy and reliability of the translations (including but not limited to local regulations, clinical guidelines, terminology, drug names and drug dosages), and is not responsible for any error and/or omissions arising from translation and adaptation or otherwise.

Open access This is an open access article distributed in accordance with the Creative Commons Attribution Non Commercial (CC BY-NC 4.0) license, which permits others to distribute, remix, adapt, build upon this work non-commercially, and license their derivative works on different terms, provided the original work is properly cited, appropriate credit is given, any changes made indicated, and the use is non-commercial. See: http://creativecommons.org/licenses/by-nc/4.0/.

ORCID iD

Eerika Rosqvist http://orcid.org/0000-0003-2217-9366

\section{REFERENCES}

1 Capella J, Smith S, Philp A, et al. Teamwork training improves the clinical care of trauma patients. J Surg Educ 2010;67:439-43.

2 Cook DA, Andersen DK, Combes JR, et al. The value proposition of simulation-based education. Surgery 2018;163:944-9.

3 Oliveira LM, Figueiredo EG. Simulation training methods in neurological surgery. Asian J Neurosurg 2019;14:364-70.

4 Armenia S, Thangamathesvaran L, Caine AD, et al. The role of highfidelity team-based simulation in acute care settings: a systematic review. Surg J 2018;4:e136-51.

5 Zendejas B, Wang AT, Brydges R, et al. Cost: the missing outcome in simulation-based medical education research: a systematic review. Surgery 2013;153:160-76.

6 Lin Y, Cheng A, Hecker K, et al. Implementing economic evaluation in simulation-based medical education: challenges and opportunities. Med Educ 2018;52:150-60.

7 Adedeji OA, Driscoll PA. The trauma team--a system of initial trauma care. Postgrad Med J 1996;72:587-93.

8 Georgiou A, Lockey DJ. The performance and assessment of hospital trauma teams. Scand J Trauma Resusc Emerg Med 2010;18:66.

9 Rosqvist E, Lauritsalo S, Paloneva J. Short 2-h in situ trauma team simulation training effectively improves non-technical skills of hospital trauma teams. Scand J Surg 2019;108:117-23.

10 Repo JP, Rosqvist E, Lauritsalo S, et al. Translatability and validation of non-technical skills scale for trauma (T-NOTECHS) for assessing simulated multi-professional trauma team resuscitations. BMC Med Educ 2019;19:40.

11 Steinemann S, Berg B, DiTullio A, et al. Assessing teamwork in the trauma bay: introduction of a modified "NOTECHS" scale for trauma. Am J Surg 2012;203:69-75.
12 Repo JP, Rosqvist E. Guidelines for translation and cross-cultural adaptation of non-technical skills rating instruments. In: Tuomi J, Ketola K, Nuutinen L, eds. Taito2016 - Oppimisen ydintä etsimässä. Tampere, Finland: Tampereen ammattikorkeakoulun julkaisuja, 2016: 19. A358. ISBN: 978-952-5903-84-3.

13 Steinemann S, Berg B, Skinner A, et al. In situ, multidisciplinary, simulation-based teamwork training improves early trauma care. $J$ Surg Educ 2011;68:472-7.

14 Lim Y-S, Steinemann S, Berg BW. Team size impact on assessment of teamwork in simulation-based trauma team training. Hawaii J Med Public Health 2014;73:358-61.

15 Pucher PH, Batrick N, Taylor D, et al. Virtual-world Hospital simulation for real-world disaster response: design and validation of a virtual reality simulator for mass casualty incident management. $J$ Trauma Acute Care Surg 2014;77:315-21.

16 Pucher PH, Aggarwal R, Batrick N, et al. Nontechnical skills performance and care processes in the management of the acute trauma patient. Surgery 2014b;155:902-9.

17 Briggs A, Raja AS, Joyce MF, et al. The role of nontechnical skills in simulated trauma resuscitation. J Surg Educ 2015;72:732-9.

18 Steinemann S, Kurosawa G, Wei A, et al. Role confusion and self-assessment in interprofessional trauma teams. Am J Surg 2016a;211:482-8.

19 Steinemann S, Bhatt A, Suares G, et al. Trauma team discord and the role of briefing. J Trauma Acute Care Surg 2016b;81:184-9.

20 DeMoor S, Abdel-Rehim S, Olmsted R, et al. Evaluating trauma team performance in a level I trauma center: validation of the trauma team communication assessment (TTCA-24). J Trauma Acute Care Surg 2017;83:159-64.

21 Sullivan S, Warner-Hillard C, Eagan B, et al. Using epistemic network analysis to identify targets for educational interventions in trauma team communication. Surgery 2018a;163:938-43.

22 Sullivan S, Campbell K, Ross JC, et al. Identifying Nontechnical skill deficits in trainees through interdisciplinary trauma simulation. J Surg Educ 2018b;75:978-83.

23 Wieck MM, McLaughlin C, Chang TP, et al. Self-assessment of team performance using T-NOTECHS in simulated pediatric trauma resuscitation is not consistent with expert assessment. Am J Surg 2018;216:630-5.

24 Cicchetti D, Bronen R, Spencer S, et al. Rating scales, scales of measurement, issues of reliability: resolving some critical issues for clinicians and researchers. J Nerv Ment Dis 2006;194:557-64.

25 Jensen AR, McLaughlin C, Wong CF, et al. Simulation-based training for trauma resuscitation among ACS TQIP-Pediatric centers: understanding prevalence of use, associated center characteristics, training factors, and implementation barriers. Am J Surg 2019;217:180-5.

26 Sollid SJM, Dieckman P, Aase K, et al. Five topics health care simulation can address to improve patient safety: results from a consensus process. J Patient Saf 2019;15:111-20.

27 Long AM, Lefebvre CM, Masneri DA, et al. The golden opportunity: multidisciplinary simulation training improves trauma team efficiency. J Surg Educ 2019;76:1116-21.

28 Knobel A, Overheu D, Gruessing M, et al. Regular, in-situ, teambased training in trauma resuscitation with video Debriefing enhances confidence and clinical efficiency. BMC Med Educ 2018;18:127.

29 Asche CV, Kim M, Brown A, et al. Communicating value in simulation: cost-benefit analysis and return on investment. Acad Emerg Med 2018;25:230-7. 